\title{
Crystalloids vs. colloids: KO at the twelfth round?
}

\author{
Dennis P Phillips 1,2, A Murat Kaynar1,2, John A Kellum and Hernando Gomez ${ }^{* 1}$ \\ University of Pittsburgh Department of Critical Care Medicine: Evidence-Based Medicine Journal Club, edited by Sachin Yende
}

\section{Expanded abstract Citation \\ Myburgh JA, Finfer S, Bellomo R, Billot L, Cass A, Gattas D, Glass P, Lipman J, Liu B, McArthur C, McGuinness S, Rajbhandari D, Taylor CB, Webb SA; CHEST Investi- gators; Australian and New Zealand Intensive Care Society Clinical Trials Group: Hydroxyethyl starch or saline for fluid resuscitation in intensive care. $N \mathrm{Engl} J$ Med 2012, 367:1901-1911.}

\section{Background}

The safety and efficacy of hydroxyethyl starch (HES) for fluid resuscitation have not been fully evaluated, and adverse effects of HES on survival and renal function have been reported.

\section{Methods \\ We randomly assigned 7,000 patients who had been admitted to an intensive care unit (ICU) in a 1:1 ratio to receive either $6 \%$ HES with a molecular weight of $130 \mathrm{kDa}$ and a molar substitution ratio of 0.4 (130/0.4, Voluven; Fresenius Kabi AG, Bad Homburg vor der Höhe, Germany) in $0.9 \%$ sodium chloride or $0.9 \%$ sodium chloride (saline) for all fluid resuscitation until ICU discharge, death, or 90 days after randomization. The primary outcome was death within 90 days. Secondary outcomes included acute kidney injury and failure and treatment with renal replacement therapy. \\ Objective: We conducted a large-scale randomized con- trolled trial to evaluate the safety and efficacy of $6 \%$ HES $(130 / 0.4)$ in $0.9 \%$ saline as compared with $0.9 \%$ saline alone for fluid resuscitation in a heterogeneous popu- lation of adult patients in the ICU. \\ Design: The Crystalloid versus Hydroxyethyl Starch Trial (CHEST) was an investigator-initiated, multicenter, prospective, blinded, parallel-group, randomized con- trolled trial.}

\footnotetext{
*Correspondence: gomezh@upmc.edu

'Department of Critical Care Medicine, University of Pittsburgh, 3550 Terrace

Street, Pittsburgh, PA 15261, USA

Full list of author information is available at the end of the article
}

Setting: The study was set at 32 hospitals in Australia and New Zealand.

Subjects: The subjects were adult patients ( $>18$ years) who were admitted to the ICU and who required intravenous fluid above maintenance requirements determined by the treating clinician and supported by at least one objective physiological criterion. Patients were excluded if they received more than $1 \mathrm{~L}$ of $6 \%$ HES within 24 hours of screening or had one of the following: dialysis-dependent or impending dialysis renal failure, computed tomography evidence of non-traumatic intracranial hemorrhage $(\mathrm{ICH})$ or severe traumatic $\mathrm{ICH}$, creatinine of more than $3.9 \mathrm{mg} / \mathrm{dL}$ or urine output of less than $10 \mathrm{~mL} /$ hour for 12 hours, sodium of more than $160 \mathrm{meq} / \mathrm{L}$, or chloride of more than $130 \mathrm{meq} / \mathrm{L}$. Also excluded were females of childbearing age (unless proven not to be pregnant) and patients who had post-cardiac surgery status, liver transplant, or burns and those whose death was judged to be imminent or whose underlying disease process indicated a life expectancy of less than 90 days.

Intervention: If fluid was deemed necessary by the treating clinician by the parameters described above, the patient received 'study' fluid with identical packaging and appearance. The fluid was either 6\% HES (130/0.4) in saline (Voluven) or $0.9 \%$ saline.

Outcomes: The primary outcome was death within 90 days. Secondary outcomes were acute kidney injury (AKI) and failure and treatment with renal replacement therapy.

\section{Results}

A total of $597(18.0 \%)$ of 3,315 patients in the HES group and $566(17.0 \%)$ of 3,336 in the saline group died (relative risk (RR) in the HES group 1.06, 95\% confidence interval (CI) 0.96 to $1.18 ; P=0.26$ ). There was no significant difference in mortality in six predefined subgroups. AKI - defined by RIFLE (Risk, Injury, Failure, Loss, and End-stage kidney disease) criteria - occurred in few patients receiving HES (34.6\%) compared with saline (38\%) (RR 0.91, 95\% CI 0.85 to 0.97). However, renal replacement therapy was used in $235(7.0 \%)$ of 3,352 patients in the HES group and 196 (5.8\%) of 3,375 in the 
saline group (RR $1.21,95 \%$ CI 1.00 to $1.45 ; P=0.04$ ). HES was significantly associated with more adverse events (5.3\% versus $2.8 \% ; P<0.001)$.

\section{Conclusions}

In patients in the ICU, there was no significant difference in 90-day mortality between patients resuscitated with $6 \%$ HES (130/0.4) or saline. However, despite a lower overall rate of AKI, more patients who received resuscitation with HES were given renal replacement therapy. (The study was supported by the National Health and Medical Research Council of Australia; the Ministry of Health, New South Wales Government, Australia; and Fresenius Kabi; and by a Practitioner Fellowship from the National Health and Medical Research Council of Australia (to Drs Myburgh and Bellomo), by a Principal Research Fellowship from the National Health and Medical Research Council of Australia (to Dr Cass), and by a Practitioner Fellowship from the Medical Research Foundation of the Royal Perth Hospital (to Dr Webb); CHEST ClinicalTrials.gov number NCT00935168.)

\section{Commentary}

The colloid-crystalloid debate has lingered for decades, resulting in the overall conclusion that composition of fluids for resuscitation does not influence morbidity or mortality in the general intensive care unit (ICU) population and that the only difference involves cost [1]. Even with the advent of 'safer' hydroxyethyl starches (HESs) [2,3], a mortality benefit remains elusive. However, human studies $[4,5]$ suggest that fluid therapies may not be as innocuous as once thought and that they may cause renal injury and perhaps affect mortality in specific subgroups.

The first adequately powered, randomized, blinded study drawing attention to these potential differential effects was the Saline versus Albumin Fluid Evaluation (SAFE) study. This study found no differences in mortality in the general ICU population but did find trends toward increased survival in patients with sepsis and increased mortality in patients with traumatic brain injury [6], suggesting that these differential effects do exist and that they may be determined by the population studied. More recently, the VISEP (Efficacy of Volume Substitution and Insulin Therapy in Severe Sepsis) trial [7] addressed the safety and efficacy of HES versus lactated ringer's solution in patients with severe sepsis and septic shock. These investigators demonstrated that HES increases risk of acute kidney injury (AKI) and renal replacement therapy. Similarly, a meta-analysis that included the VISEP trial showed an increased risk of AKI in the general population and an increased risk of AKI and use of renal replacement therapy in patients with sepsis. However, the VISEP trial used high doses of hyperoncotic HES and may not be relevant to usual practice. Finally, a meta-analysis by Perel and colleagues [8], which included both SAFE and VISEP trials, failed to show differences in mortality in hospitalized patients but recommended that future trials focus on specific subgroups. Taken together, these data suggested that fluid composition may be important, at least in certain subgroups of critically ill patients, especially in patients with sepsis. The Scandinavian $6 \mathrm{~S}$ trial attempted to answer this question by randomly assigning patients with severe sepsis to receive HES in a ringer's acetate solution compared with carrier solution alone. The $6 \mathrm{~S}$ trial found a higher risk of 90-day mortality (relative risk $=1.17$, $P=0.03$ ) and greater use of renal replacement therapy with HES as compared with those receiving ringer's acetate [9]. However, whether the increased mortality and morbidity risk were present in a more heterogeneous ICU population was still unknown. Whether other forms of HES carry a similar risk is also unclear from the $6 \mathrm{~S}$ trial. The Crystalloid versus Hydroxyethyl Starch Trial (CHEST) sought to answer these questions.

CHEST was a well-conducted, blinded, randomized trial that used a patient-centered outcome such as 90-day mortality as the primary aim and that was adequately powered to find differences between groups using the intention-to-treat principle. The authors were cautious to ensure that the intervention fluids of the two arms of the study had the expected composition by performing independent and random biochemical analyses. In addition, the study targeted a more general ICU patient population, as compared to other recent clinical trials evaluating crystalloids versus colloids, such as 6S. Importantly, the CHEST was designed to allow for a difference in fluid volumes between each arm, whereas $6 \mathrm{~S}$ proscribed equal volumes. Limitations to this study include the following: (a) predefined criteria for the initiation of renal replacement therapy were absent, (b) the observed death rate was lower than the predicted death rate, and this may lead to difficulties in detecting mortality differences, (c) the patients who were less sick (than $6 \mathrm{~S}$ trial) and elective surgical patients were included, and (d) the time to resolution of the objective parameter (heart rate, blood pressure, respiratory variation of systolic or mean arterial blood pressure, central venous pressure, capillary refill, and urine output) used to support a diagnosis of hypovolemia was not compared between the groups.

The CHEST found no difference in 90-day mortality between patients receiving 6\% HES (130/0.4) and those receiving $0.9 \%$ saline. Interestingly, the use of renal replacement therapy was greater in patients receiving HES, even though by RIFLE (Risk, Injury, Failure, Loss, and End-stage kidney disease) criteria the saline group had more AKI. Post hoc analysis suggested that increases in creatinine were more pronounced in the HES group, 
perhaps prompting the small but significant increased use of renal replacement therapy. Shaw and Kellum [10] (2013) theorize that this paradox may be explained by a reduction in glomerular filtration rate by HES despite better early urine output due to more effective volume expansion with the colloid. Furthermore, clinicians may be trading short-term improvements in hemodynamics and urine flow for long-term renal toxicity [10]. Whether some patients would benefit from better resuscitation efficiency (that is, achieving resuscitation goals faster with less fluid) even at the expense of some renal toxicity cannot be addressed by this or the $6 \mathrm{~S}$ trial. Finally, the CHEST enrolled patients an average of 11 hours after ICU admission, and most $6 \mathrm{~S}$ patients were already resuscitated prior to study entry. Thus, these aspects of the colloid-crystalloid debate rage on. It will be important to see the one-year outcome follow-up data yet to be published. In the meantime, the existing data confirm a renal toxicity signal from HES not only in patients with sepsis but also in the general ICU population.

\section{Recommendations}

Given this evidence of renal toxicity and in spite of the uncertainty of the effect on resuscitation efficiency, we believe that HES should be avoided in patients with severe sepsis as well as in other critically ill patients at high risk of AKI. There is no doubt that the colloidcrystalloid debate has been informed by these two trials. However, the remaining uncertainty on aspects such as resuscitation efficiency and timing of intervention just might gather enough rumble for a thirteenth round.

\section{Abbreviations}

AKI, acute kidney injury; CHEST, Crystalloid versus Hydroxyethyl Starch Trial; HES, hydroxyethyl starch; ICU, intensive care unit; SAFE, Saline versus Albumin Fluid Evaluation; VISEP, Efficacy of Volume Substitution and Insulin Therapy in Severe Sepsis.

\section{Competing interests}

The authors declare that they have no competing interests.

\section{Author details}

'Department of Critical Care Medicine, University of Pittsburgh, 3550 Terrace Street, Pittsburgh, PA 15261, USA. 2Department of Anesthesiology, University of Pittsburgh, 3550 Terrace Street, Pittsburgh, PA 15261, USA.

\section{Published: 29 May 2013}

\section{References}

1. Finfer S, Bellomo R, Boyce N, French J, Myburgh J, Norton R; SAFE Study Investigators: A comparison of albumin and saline for fluid resuscitation in the intensive care unit. NEngl J Med 2004, 350:2247-2256.

2. Zarychanski R, Turgeon AF, Fergusson DA, Cook DJ, Hébert P, Bagshaw SM, Monsour D, McIntyre L: Renal outcomes and mortality following hydroxyethyl starch resuscitation of critically ill patients: systemic review and meta-analysis of randomized trials. Open Med 2009, 3:e196-e209.

3. Bunn F, Trivedi D, Ashraf S: Colloid solutions for fluid resuscitation. Cochrane Database Syst Rev 2008, (1):CD001319.

4 Barron ME, Wilkes MM, Navickis RJ: A systematic review of the comparative safety of colloids. Arch Surg 2004, 139:552-563.

5. Wikes MM, Navickis RJ, Sibbald WJ: Albumin versus hydroxyethyl starch in cardiopulmonary bypass surgery: a meta-analysis of postoperative bleeding. Ann Thorac Surg 2001, 72:527-533; discussion 534.

6. SAFE Study Investigators; Australian and New Zealand Intensive Care Society Clinical Trials Group; Australian Red Cross Blood Service; George Institute for International Health, Myburgh J, Cooper DJ, Finfer S, Bellomo R, Norton R, Bishop N, Kai Lo S, Vallance S: Saline or albumin for fluid resuscitation in patients with traumatic brain injury. N Engl J Med 2007, 357:874-884.

7. Brunkhorst FM, Engel C, Bloos F, Meier-Hellmann A, Ragaller M, Weiler N, Moerer O, Gruendling M, Oppert M, Grond S, Olthoff D, Jaschinski U, John S, Rossaint R, Welte T, Schaefer M, Kern P, Kuhnt E, Kiehntopf M, Hartog C, Natanson C, Loeffler M, Reinhart K; German Competence Network Sepsis (SepNet): Intensive insulin therapy and pentastarch resuscitation in severe sepsis. N Engl J Med 2008, 358:125-139.

8. Perel P, Roberts I: Colloids versus crystalloids for fluid resuscitation in critically ill patients. Cochrane Database Syst Rev 2012, 6:CD000567.

9. Perner A, Haase N, Guttormsen AB, Tenhunen J, Klemenzson G, Åneman A Madsen KR, Møller MH, Elkjær JM, Poulsen LM, Bendtsen A, Winding R, Steensen M, Berezowicz P, Søe-Jensen P, Bestle M, Strand K, Wiis J, White JO, Thornberg KJ, Quist L, Nielsen J, Andersen LH, Holst LB, Thormar K, Kjæeldgaard AL, Fabritius ML, Mondrup F, Pott FC, Møller TP, Winkel P, Wetterslev J; 6S Trial Group; Scandinavian Critical Care Trials Group: Hydroxyethyl starch 130/0.42 versus Ringer's acetate in severe sepsis. N Engl J Med 2012, 367:124-134.

10. Shaw AD, Kellum JA: The risk of AKI in patients treated with intravenous solutions containing hydroxyethyl starch. Clin J Am Soc Nephrol 2013, 8:497-503.

doi:10.1186/cc12708

Cite this article as: Phillips DP, et al.: Crystalloids vs. colloids: $\mathrm{KO}$ at the twelfth round? Critical Care 2013, 17:319. 